\title{
Cirurgia de catarata: o porquê dos excluídos ${ }^{1}$
}

\author{
Newton Kara-José ${ }^{2}$ e Edméa Rita Temporini ${ }^{2}$
}

RESUMO A catarata é a principal causa de cegueira no mundo, embora seja passível de recuperação por intervenção cirúrgica relativamente simples e de baixo custo. O presente estudo, realizado em 1997 e 1998 em cinco municípios do Estado de São Paulo, Brasil, teve o propósito de identificar as razões para a falta de acesso ao tratamento cirúrgico por parte dos deficientes visuais por catarata senil. Foram entrevistados pacientes atendidos em um projeto comunitário de reabilitação da cegueira por catarata, o Projeto Zona Livre de Catarata. Obteve-se uma amostra prontamente acessível, composta por 776 sujeitos que procuraram a assistência do projeto e que apresentavam acuidade visual menor do que 0,2 no olho melhor (média de idade $=70$ anos). Foi aplicado um questionário por entrevista. Dentre os pacientes, 683 haviam procurado atendimento oftalmológico antes do Projeto Catarata; o tipo mais comum de atendimento procurado foi o serviço público de saúde (27\%). Dificuldades financeiras $(69 \%)$ e ainda enxergar bem (69\%) foram as razões predominantes alegadas pelos pacientes para não terem se submetido à cirurgia de catarata. Dentre os que manifestaram receio da cirurgia, a principal alegação foi medo de ficar cego. Todos os pacientes que receberam indicação cirúrgica no período do estudo concordaram em se submeter à cirurgia. Aparentemente, existe uma lacuna entre a busca de serviços oftalmológicos e a resolução cirúrgica da catarata. Os fatores predominantes para a não realização da cirurgia foram econômicos e logísticos. É necessário facilitar o acesso da população à cirurgia de catarata por meio de modelos assistenciais descentralizados e de projetos e campanhas comunitárias de prevenção da cegueira por catarata.

A perda da capacidade visual acarreta conseqüências adversas, em nível individual e coletivo. A cegueira dá origem a problemas psicológicos, sociais, econômicos e de qualidade de vida, pois implica em perda de autoestima, de status, em restrições ocupacionais e em conseqüente diminuição

\footnotetext{
1 Baseado em projeto de pesquisa financiado pela Fundação de Amparo à Pesquisa do Estado de São Paulo (FAPESP), processo $\mathrm{n}^{\circ}$ 97/01848-9.

2 Universidade Estadual de Campinas (UNICAMP), Faculdade de Ciências Médicas, Departamento de Oftalmologia. Correspondência e pedidos de separatas devem ser enviados a Newton Kara-José no seguinte endereço: Rua Madre Teodora 281, Jardim Paulista, CEP 01428-010, São Paulo, SP, Brasil. Fax: +55-11-816-2287.
}

de renda, que, por sua vez, produz dificuldades de sobrevivência. Para a sociedade, representa encargo oneroso e perda de força de trabalho $(1,2)$.

A catarata, reconhecidamente, constitui a principal causa de cegueira no mundo, passível de recuperação por intervenção cirúrgica apropriada $(2,3)$. As técnicas de remoção da opacidade lenticular, na atualidade, apresentam-se relativamente simples, têm baixo custo e têm sido praticadas com segurança há muitos anos (4). Entretanto, freqüentemente observam-se limitações no acesso à cirurgia ocular, por dificuldades diversas referentes ao paciente (5, 6) ou por obstáculos impostos pelo próprio sistema de saúde e que impe- dem a utilização do recurso cirúrgico em sua plena potencialidade (7). A deficiência na prestação de assistência à saúde inclui a dificuldade de acesso à cirurgia ocular.

Os resultados de estudos sobre aspectos sociais da realização da cirurgia de catarata senil conduzidos em Campinas, Brasil, e Chimbote, Peru, revelaram que $50 \%$ dos casos de cegueira por catarata se deviam à ausência da intervenção cirúrgica específica (8).

Desde 1987, desenvolveu-se no Estado de São Paulo um programa de prevenção da cegueira por catarata, composto por projetos denominados Zona Livre de Catarata, ou, abreviadamente, Projeto Catarata. O Projeto Ca- 
tarata procura eliminar obstáculos logísticos para que o indivíduo deficiente visual por catarata receba o tratamento necessário mediante a facilitação do acesso ao exame oftalmológico e à cirurgia, assim como através de processo educativo da população. Esse projeto é realizado em dias de final de semana - em geral, um sábado e um domingo - em local que privilegia critério geográfico de proximidade das residências. Faz-se divulgação prévia intensa do projeto, local e datas para o atendimento da comunidade.

Inicialmente, a iniciativa para executar o projeto foi da disciplina de oftalmologia, através do Núcleo de Prevenção da Cegueira da Faculdade de Ciências Médicas da Universidade Estadual de Campinas (UNICAMP), tendo recebido, posteriormente, apoio internacional do National Eye Institute (EUA), Helen Keller International, Associação Pan-Americana de Oftalmologia e Lyons International Foundation. Esse programa baseia-se nas recomendações da Associação PanAmericana de Oftalmologia (1985) (9), segundo as quais deve-se unir esforços para identificar, em populações definidas e em tempo determinado, indivíduos de mais de 50 anos de idade, portadores de cegueira por catarata, a fim de proporcionar-lhes o tratamento cirúrgico necessário. Confere-se prioridade às intervenções direcionadas a populações de baixa renda e que apresentem dificuldade de acesso a serviços especializados (10).

Kara-José et al. (11) ressaltam a necessidade de vencer o desafio da cegueira por catarata na população idosa brasileira, por meio do aumento significativo do número de cirurgias de catarata realizadas nas instituições públicas que prestam serviços ao sistema público de saúde. Reiteram, ainda, a importância da participação dos oftalmologistas nesse processo e em programas comunitários de reabilitação visual.

A ação preventiva em saúde, no entanto, exige participação consciente do indivíduo afetado no sentido de adotar ou mudar comportamentos (1). É, portanto, necessário criar condições que motivem os indivíduos afetados, facilitar seu acesso aos serviços de saúde e organizar estes serviços adequadamente (7).

O conhecimento sobre o que as pessoas sabem, desejam, percebem e fazem em relação à prevenção e assistência de problemas oculares é um prérequisito importante para a realização do planejamento de ações e programas de prevenção da cegueira, bem como para a organização de serviços assistenciais. Esse conhecimento deve ser obtido por meio da pesquisa de variáveis sócio-comportamentais, com a intenção de identificar percepções e conduta de adultos portadores de catarata senil em relação à doença e ao tratamento cirúrgico (1). Nesta pesquisa procurou-se identificar razões de deficientes visuais por catarata senil para explicar a ausência de acesso anterior ao tratamento cirúrgico, a fim de ampliar o conhecimento de aspectos sociais relacionados à reabilitação visual.

\section{MATERIAIS E MÉTODOS}

Procedeu-se ao levantamento de dados relativos à população que compareceu aos postos de atendimento oftalmológico, instalados para as atividades do Projeto Catarata nos municípios de Campinas, São Paulo, Taquaritinga, Bebedouro e Bragança Paulista, no Estado de São Paulo. Autoridades de saúde desses municípios manifestaram interesse na execução do projeto. Os dados foram coletados em 1997 e 1998, conforme cronograma planejado para a execução dos projetos de reabilitação visual.

Para obtenção da amostra estabeleceram-se os seguintes critérios: indivíduos de ambos os sexos, de idade igual ou superior a 50 anos, portadores de deficiência visual por catarata senil (acuidade visual igual ou inferior a 0,2 no olho melhor), que se dispusessem a ser entrevistados. Esses indivíduos conseguem realizar algumas atividades domésticas, mas apresentam dificuldade acentuada na locomoção sem auxílio, na utilização de transporte em veículo coletivo e no exercício de atividade profissional. Compôs-se, portanto, uma amostra não probabilística, prontamente acessível.
A partir de um estudo preliminar, construiu-se um questionário (anexo 1) que forneceu elementos para a elaboração de questões estruturadas. O instrumento foi submetido a teste prévio durante a realização do Projeto Catarata em outro município do Estado de São Paulo, não pertencente à amostra.

Para caracterizar a amostra foram selecionadas as variáveis sexo, idade e município do atendimento oftalmológico. Foram estudados o conhecimento anterior do fato de ser portador de catarata, a percepção da gravidade dessa afecção, o tipo de serviço médico procurado anteriormente e as razões para a ausência de tratamento cirúrgico. $\mathrm{O}$ questionário foi aplicado em entrevista por auxiliares de pesquisa previamente treinados para a formulação das questões e registro de respostas. Os dados foram processados em microcomputador, utilizando-se o sistema Epi Info.

\section{RESULTADOS}

A amostra foi composta por $776 \mathrm{su}$ jeitos de ambos os sexos (47\% homens; $53 \%$ mulheres), com idade entre 50 e 96 anos. A média de idade foi de 72 anos (desvio padrão de 8,46 ) e a moda alcançou 70 anos de idade. Este grupo de 776 sujeitos correspondeu à parcela da população atendida nos projetos comunitários de reabilitação visual (Projeto Catarata) realizados em cinco municípios do Estado de São Paulo e que, após exames oftalmológicos, recebeu indicação cirúrgica para tratamento da catarata senil. A amostra distribui-se da seguinte forma entre os municípios que participaram do estudo: Campinas (35\%); São Paulo (21\%); Taquaritinga (17\%); Bebedouro (15\%); e Bragança Paulista (10\%). No momento da pesquisa, $74 \%$ dos sujeitos dispunham de acompanhante.

A maior parcela dos entrevistados apresentava conhecimento anterior do fato de ser portador de catarata $(78 \%)$ e atribuía gravidade a essa afecção $(65 \%)$ (tabela 1). Dentre os entrevistados que haviam procurado consultas oftalmológicas antes do Projeto Catarata ( $n=683)$, a maior parcela havia utilizado o serviço de saúde do sis- 
TABELA 1. Conhecimento anterior do fato de ser portador de catarata e percepção da gravidade dessa doença: pacientes do Projeto Catarata, Estado de São Paulo, Brasil, 1997 e 1998

\begin{tabular}{lcr}
\hline Percepção em relação à catarata $(n=776)$ & No. & $\%$ \\
\hline Sabia da catarata & & \\
Sim & 604 & 78 \\
Não & 172 & 22 \\
Gravidade atribuída & 134 & 17 \\
Muito grave & 368 & 47 \\
Grave & 121 & 16 \\
Mais ou menos grave & 102 & 13 \\
Pouco/nada grave & 51 & 7 \\
Não sabe & & \\
\hline
\end{tabular}

tema público como atendimento único $(27 \%)$ ou em associação ao sistema previdenciário $(4 \%)$ e ao consultório oftalmológico particular (3\%); $10 \%$ haviam procurado o Hospital das Clínicas/UNICAMP (tabela 2). Além disso, $11 \%$ mencionaram outros tipos de serviço (tabela 2).

A ausência de tratamento cirúrgico da catarata foi explicada pelos sujeitos por dificuldade financeira $(69 \%)$ e pelo fato de, na ocasião da entrevista, admitirem conservar ainda visão razoável (69\%) (tabela 3).

Embora todos tenham concordado em se submeter à cirurgia ocular, $22 \%$ manifestaram receio. Entre as razões mencionadas para esse temor destacou-se a possibilidade de ficar cego em conseqüência da cirurgia (64\%). Esta alegação superou a alegação de medo da morte (22\%) (tabela 4).

TABELA 2. Tipo de serviço de saúde procurado por portadores de catarata para atendimento oftalmológico antes do atendimento pelo Projeto Catarata: respostas associadas, Estado de São Paulo, Brasil, 1997 e 1998

\begin{tabular}{|c|c|c|c|c|c|c|}
\hline \multirow{2}{*}{\multicolumn{2}{|c|}{$\begin{array}{l}\text { Respondentes } \\
\quad(n=683)\end{array}$}} & \multicolumn{5}{|c|}{ Formas de associação das respostas } \\
\hline & & \multirow{2}{*}{$\begin{array}{l}\text { Posto de } \\
\text { saúde }\end{array}$} & \multirow{2}{*}{$\begin{array}{c}\text { INPS/ } \\
\text { FUNRURAL }{ }^{\mathrm{a}, \mathrm{b}}\end{array}$} & \multirow{2}{*}{$\begin{array}{l}\text { Consultório } \\
\text { particular }\end{array}$} & \multirow{2}{*}{$\begin{array}{c}\text { Hospital das } \\
\text { Clínicas/UNICAMPa,c }\end{array}$} & \multirow{2}{*}{$\begin{array}{l}\text { Consultório } \\
\text { de convênio }\end{array}$} \\
\hline No. & $\%$ & & & & & \\
\hline 188 & 27 & • & & & & \\
\hline 134 & 20 & & • & & & \\
\hline 128 & 19 & & & • & & \\
\hline 67 & 10 & & & & • & \\
\hline 45 & 7 & & & & & • \\
\hline 26 & 4 & • & • & & & \\
\hline 19 & 3 & • & & • & & \\
\hline $607^{d}$ & 89 & & & & & \\
\hline
\end{tabular}

a Serviços institucionais gratuitos.

b Sistema de saúde previdenciário.

c Hospital das Clínicas da Universidade Estadual de Campinas.

d Os demais respondentes (11\%) forneceram outras formas de associação.
O Projeto Zona Livre de Catarata tem o propósito de reduzir o número de cegos por catarata a um nível suportável para a sociedade e passível de manutenção posterior por intermédio de um programa continuado. Este projeto tem demonstrado a exeqüibilidade do tratamento cirúrgico mediante racionalização e otimização de recursos. Além disso, evita a necessidade de múltiplos deslocamentos do paciente aos locais de consulta; na maioria dos hospitais-escola do país, o tratamento é concluído somente após cerca de 10 retornos. Essa dificuldade, associada à dificuldade de locomoção e à necessidade de ter um acompanhante para chegar até o local da consulta, acaba por constituir um obstáculo de difícil transposição para os deficientes visuais de baixa renda (9).

É lícito supor que o retardo ou a ausência de procura por assistência oftalmológica não dependem inteiramente do desconhecimento do indivíduo a respeito de ser portador de catarata ou do tipo de tratamento necessário. Esse fato evidenciou-se nos resultados da tabela 1, onde os entrevistados reconheciam a presença e a gravidade do seu problema visual. $O$ fator econômico parece assumir importância maior dentre as dificuldades mencionadas para a obtenção de consulta oftalmológica (tabela 3).

De outro lado, barreiras psicológicas e educacionais parecem ser ultrapassadas por meio da divulgação efetiva a respeito de atendimento oftalmológico próximo ao local de residência do paciente, como em geral é o procedimento preliminar à realização de projeto comunitário de catarata. Esse critério de proximidade reduz consideravelmente a necessidade de gastos por parte do paciente e do acompanhante. Note-se que $74 \%$ dos entrevistados dispunham de acompanhante, medida recomendável para superar dificuldades de locomoção em ambientes estranhos, mas que implica em gastos duplos. Quando se realiza o atendimento em fim de semana e na área de residência ou proximidades, elimina-se perda do dia de trabalho do acompanhante e reduz-se o gasto com o transporte de ambos (6). Assim, as razões de 
TABELA 3. Razões alegadas para ausência de tratamento cirúrgico anterior da catarata, pacientes atendidos pelo Projeto Catarata, Estado de São Paulo, Brasil, 1997 e 1998

\begin{tabular}{lccc}
\hline \multicolumn{1}{c}{ Razões $(n=776)^{\text {a }}$} & Sim (\%) & Não (\%) & Não lembra (\%) \\
\hline Falta de dinheiro & 69 & 30 & 1 \\
Ainda enxergava bem & 69 & 30 & 1 \\
Acesso difícil a oftalmologista & 28 & 71 & 1 \\
Não contava com acompanhante & 15 & 84 & 1 \\
Não podia faltar ao trabalho & 8 & 91 & 1 \\
\hline
\end{tabular}

${ }^{a}$ Respostas múltiplas. falta de dinheiro e de acompanhante citadas pelos respondentes interligamse, de certa forma, para explicar a ausência de tratamento anterior.

$\mathrm{O}$ fato de terem admitido "ainda enxergar bem", ou de terem medo da cirurgia, pode ser interpretado como auto-justificativa na ocasião, tendo em vista que procuraram o atendimento oferecido pelo Projeto Catarata e aceitaram a indicação cirúrgica.

É admissível supor a existência de lacuna entre a procura do atendimento oftalmológico e a resolução efetiva do problema visual. Assim, $88 \%$ dos sujeitos referiram busca anterior de serviços oftalmológicos diversos (tabela 2). Contudo, o fato de terem acorrido ao projeto Catarata mostra que o problema não havia sido solucionado. Pode-se supor que o medo, conformismo ou falta de confiança no resultado cirúrgico possam ter influído; porém, a aceitação da indicação cirúrgica por todos os portadores de catarata atendidos no projeto sugere que os fatores preponderantes para a exclusão anterior à cirurgia foram econômicos ou logísticos.
Além disso, é importante ressaltar que, embora a grande maioria dos pacientes (89\%) tenha tido acesso à consulta clínica em serviços de saúde públicos e privados, estes pacientes não conseguirem se submeter à cirurgia.

Comparado à América Latina, o Brasil pode ser considerado um país privilegiado no que se refere ao contingente disponível de oftalmologistas. Apesar da má distribuição geográfica desses especialistas, existe número suficiente para resolver o problema da catarata e de muitos outros causadores da cegueira. No Brasil, estima-se a existência de 90000 casos operáveis de catarata por ano. Se cada oftalmologista realizasse oito cirurgias por mês, todos os indivíduos com indicação cirúrgica seriam operados (10).

Outro fator de dificuldade, contudo, consiste na falta ou insuficiência de facilidades cirúrgicas em muitas cidades ou regiões. A realização de cirurgia de catarata com subvenção do Sistema Único de Saúde (SUS) não é do interesse de grande parte dos oftalmologistas (11). Na maioria das vezes, porém, o
TABELA 4. Medo de submeter-se à cirurgia ocular entre portadores de catarata, Estado de São Paulo, Brasil, 1997 e 1998

\begin{tabular}{lrr}
\hline \multicolumn{1}{c}{ Variável } & No. & $\%$ \\
\hline Medo da cirurgia $(n=776)$ & & \\
Sim & 171 & 22 \\
Não & 598 & 77 \\
Não sabe & 7 & 1 \\
Razões para ter medo da cirurgia $(n=171)^{\mathrm{a}}$ & 110 & 64 \\
Pode ficar cego & 58 & 34 \\
Tem outro problema de saúde & 45 & 26 \\
Conhecido fez e piorou & 38 & 22 \\
Pode morrer & 36 & 21 \\
Religião não permite & &
\end{tabular}

a Respostas múltiplas. real fator limitante diz respeito ao limite do número de cirurgias imposto pelas autoridades de saúde, decorrente da limitação de recursos financeiros destinados à assistência médica. Essa política pode até ser compreensível em virtude dos limitados recursos governamentais, porém torna-se inaceitável no que concerne à cirurgia de catarata. O custo relativamente baixo (cerca de 230 dólares, com implante de lente intra-ocular) desta cirurgia converte-se em extraordinário retorno em relação à qualidade de vida e, mesmo, de cunho econômico para esses pacientes. A erradicação (ou controle) da cegueira por catarata, além de beneficiar o paciente e sua família, constitui também investimento social de alta relação custo/benefício (14). Estima-se que, com o modelo atual de acesso à cirurgia, $90 \%$ dos deficientes visuais por catarata não seriam reabilitados. Pesquisas realizadas permitiram estimar em $10 \%$ a proporção de indivíduos que se submetem à cirurgia de catarata, dentre os que necessitam ser operados $(5,6,8,10,12)$.

Admite-se, assim, que a descentralização de serviços hospitalares, por meio da criação de serviços oftalmológicos regionalizados e de postos hospitalares de catarata, ao lado de uma política governamental de livre acesso à cirurgia de catarata, poderá contribuir efetivamente para a ampliação necessária do número de cirurgias de catarata senil na população brasileira.

Enquanto o sistema de saúde não apresentar soluções definitivas para o problema, cabe reforçar o alcance e a importância das campanhas e projetos comunitários de prevenção da cegueira por catarata, reabilitando a visão do indivíduo. Como já foi dito anteriormente, voltar a enxergar significa, para muitos pacientes, uma volta à vida e uma reconquista da dignidade e do respeito próprio (15).

Agradecimentos. Agradecemos à Fundação de Amparo à Pesquisa do Estado de São Paulo (FAPESP) o apoio financeiro a este projeto, e às autoridades municipais envolvidas no Projeto Catarata a facilitação de condições para sua execução. 


\section{REFERÊNCIAS}

1. Temporini ER, Kara-José N. Níveis de prevenção de problemas oftalmológicos: propostas de investigação. Arq Bras Oftalmol 1995; 58(3):189-192.

2. Thylefors B. Much blindness is avoidable. World Health Forum 1991;12(1):78-86.

3. World Health Organization. Strategies for the prevention of blindness in national programmes: a primary health care approach. Geneva: WHO; 1984.

4. Minassian DC. Epidemiological methods in prevention of blindness. Eye 1998;2(suppl): S3-S12.

5. Kara-José N, Arieta CEL, Temporini ER, Kang KM, Ambrósio LE. Tratamento cirúrgico de catarata senil: óbices para o paciente. Arq Bras Oftalmol 1996;59(6):573-577.

6. Temporini ER, Kara-José N, Kara-José Jr N. Catarata senil: características e percepções de pacientes atendidos em projeto comunitário de reabilitação visual. Arq Bras Oftalmol 1997;60(1):79-83.
7. Sommer A. Organizing to prevent third world blindness. Am J Ophthalmol 1989;107(5): 544-546.

8. Kara-José N, Contreras F, Campos MA, Delgado AM, Mowery RL, Ellwein LB. Screening and surgical intervention results from cataract free zone projects in Campinas, Brazil and Chimbote, Peru. Int Ophthalmol 1990;14(1): 155-164.

9. Delgado MN, Kara-José N. Projetos comunitários em oftalmologia. Em: Kara-José N, org. Prevenção de cegueira por catarata. Campinas: Editora da UNICAMP; 1996. p. 55-70.

10. Kara-José N, org. Prevenção de cegueira por catarata. Campinas: Editora da UNICAMP; 1996.

11. Kara-José N, Arieta CEL, Delgado AN. Exeqüibilidade da cirurgia de catarata em hospitalescola: em busca de um modelo econômico. Rev Assoc Med Bras 1994;40(3):186-188.

12. Prado Jr J, Silva ALB, Alves MR, Kara-José N, Temporini ER. Tratamento cirúrgico da cata- rata senil no Hospital das Clínicas da Faculdade de Medicina da Universidade de São Paulo-aspectos da rotina operacional. Rev Medicina São Paulo 1997;76(3):192-196.

13. Kara-José Jr N, Schellini SA, Silva MRBM, Bruni LF, Almeida AGC. Projeto catarataqual a sua importância para a comunidade? Arq Bras Oftalmol 1996;59(6):490-496.

14. Javitt JC. The cost-effectiveness of restoring sight. Arch Ophthalmol 1993;111(12):1615.

15. Kara-José N, Almeida GV, Alves MR, Kikuta HS, Arieta CEL. Campanha nacional de prevenção de cegueira e reabilitação visual do idoso-1996. Rev Medicina São Paulo 1997; 76(3):293-296.

Manuscrito recebido em 3 de junho de 1998. Aceito em versão revisada em 15 de abril de 1999.

\section{ANEXO 1}

Pesquisa - Catarata senil: características, percepção e conduta do paciente - 1996

Questionário no.

$\frac{7}{2} \quad \overline{3}$

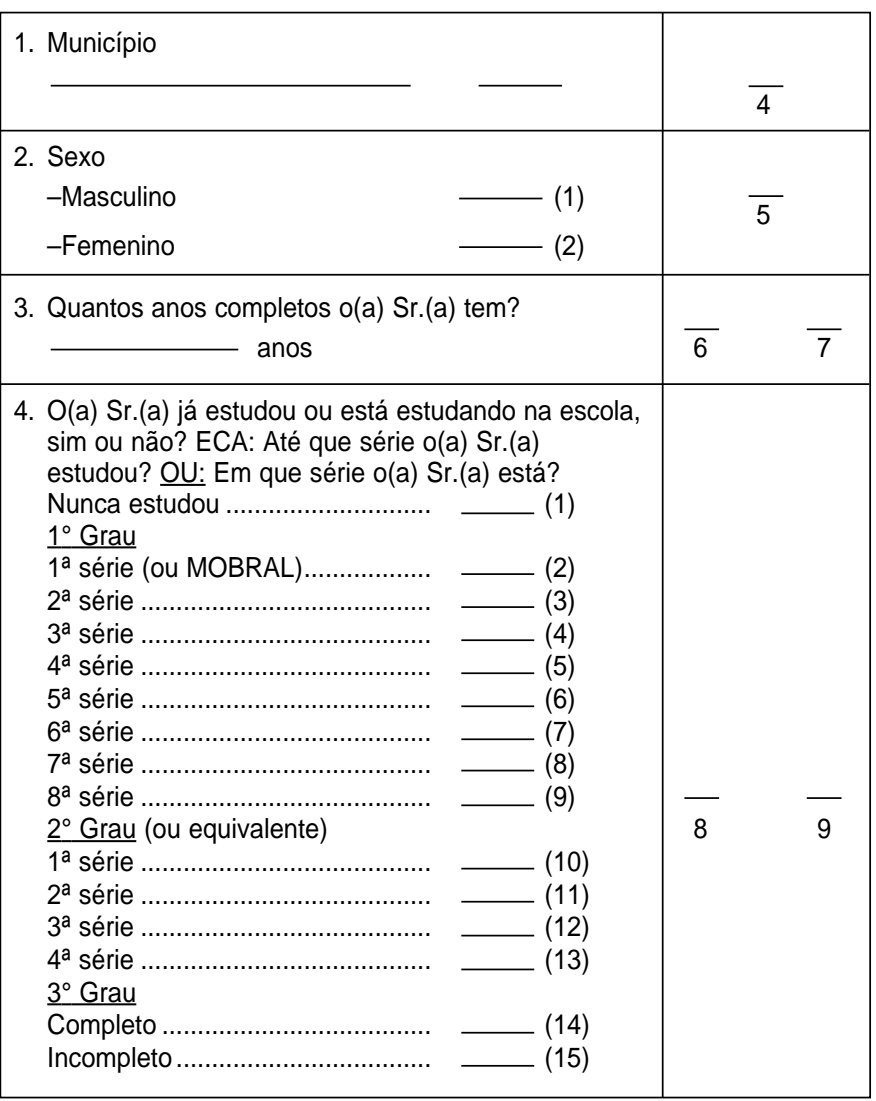

\begin{tabular}{|c|c|}
\hline $\begin{array}{l}\text { 5. Atualmente, o(a) Sr.(a) trabalha e recebe algum } \\
\text { pagamento pelo seu trabalho, sim ou não? } \\
\text {-Sim }\end{array}$ & $\overline{10}$ \\
\hline $\begin{array}{l}\text { 6. Alguém acompanhou o(a) Sr.(a) hoje, para } \\
\text { vir fazer exame de vista, ou veio sozinho(a)? } \\
\text {-Teve acompanhante................... } \\
\text {-Não teve acompanhante ............. }\end{array}$ & $\overline{11}$ \\
\hline $\begin{array}{l}\text { 7. O(a) Sr.(a) já sabia que tinha catarata nos } \\
\text { olhos, antes do exame de vista que fez hoje, } \\
\text { Sim ou não? } \\
\text {-Sim ................................... (1) }\end{array}$ & $\frac{}{12}$ \\
\hline 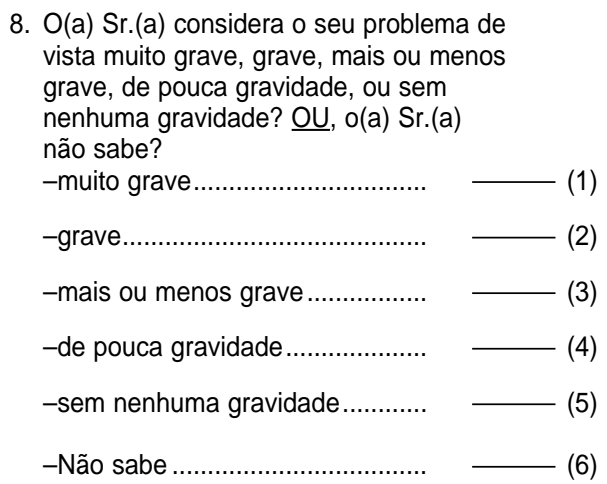 & $\frac{1}{13}$ \\
\hline
\end{tabular}




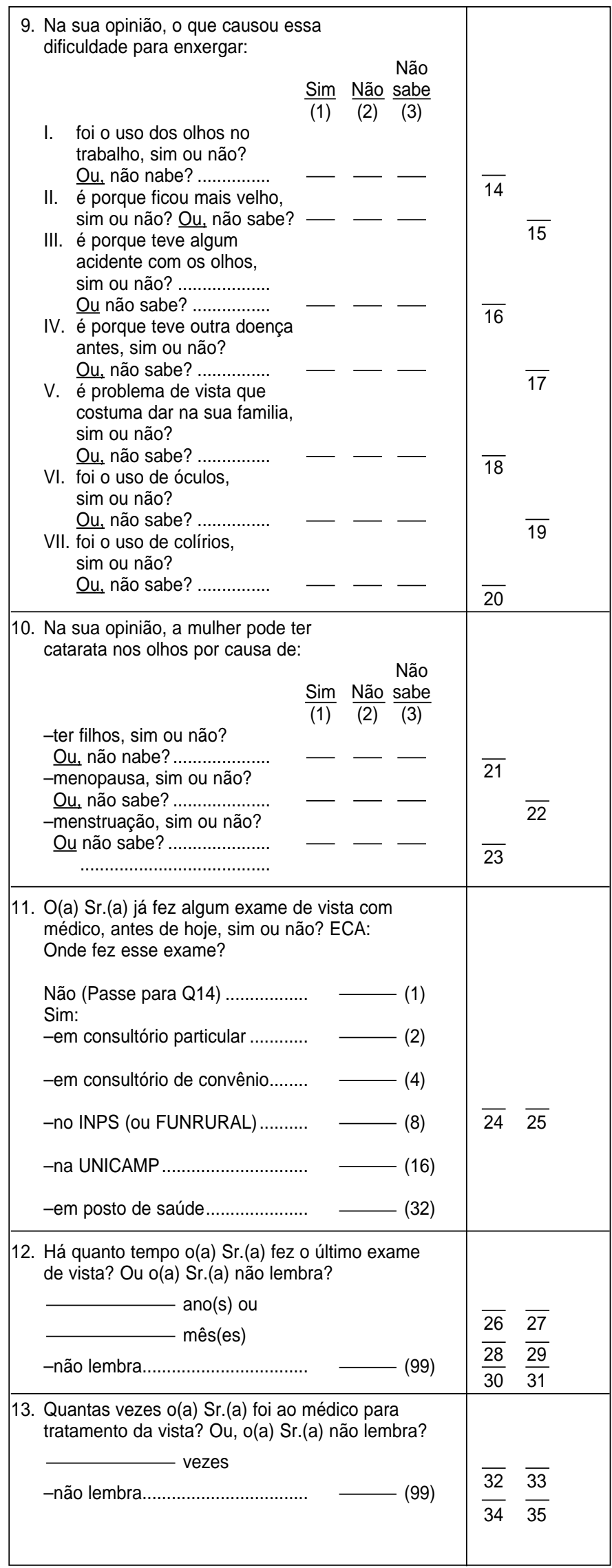

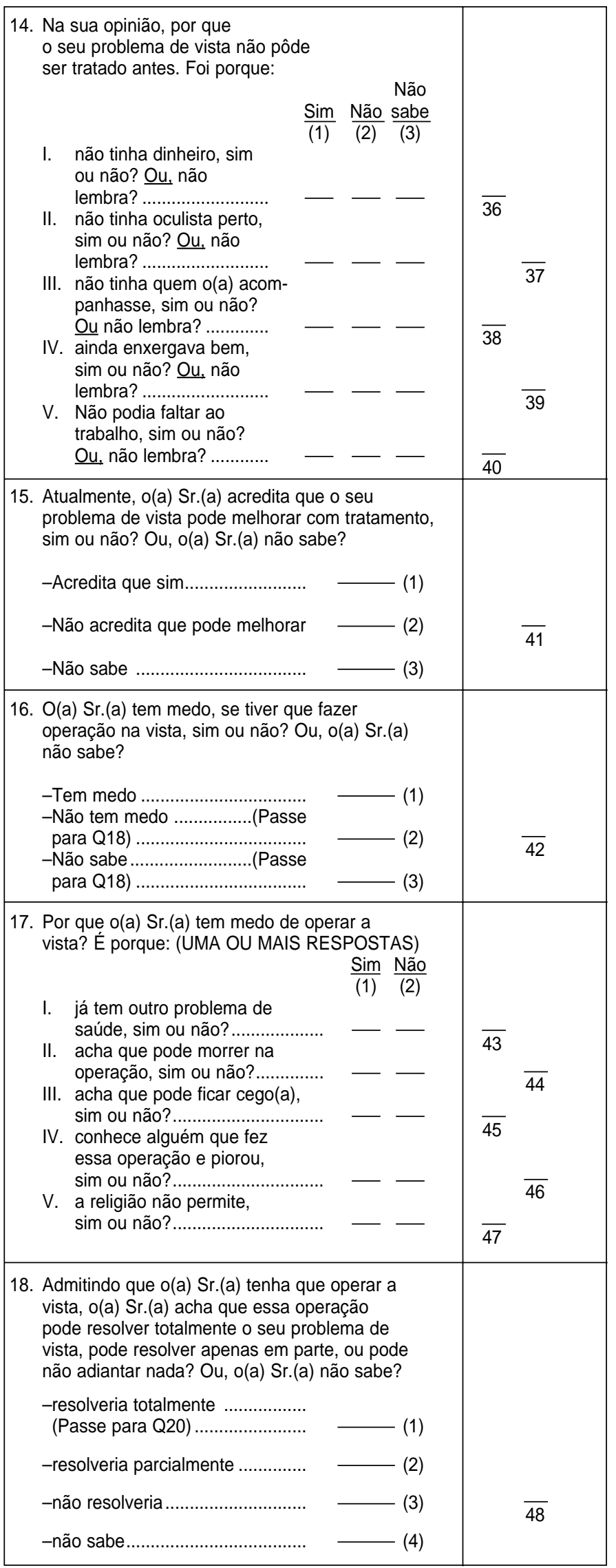




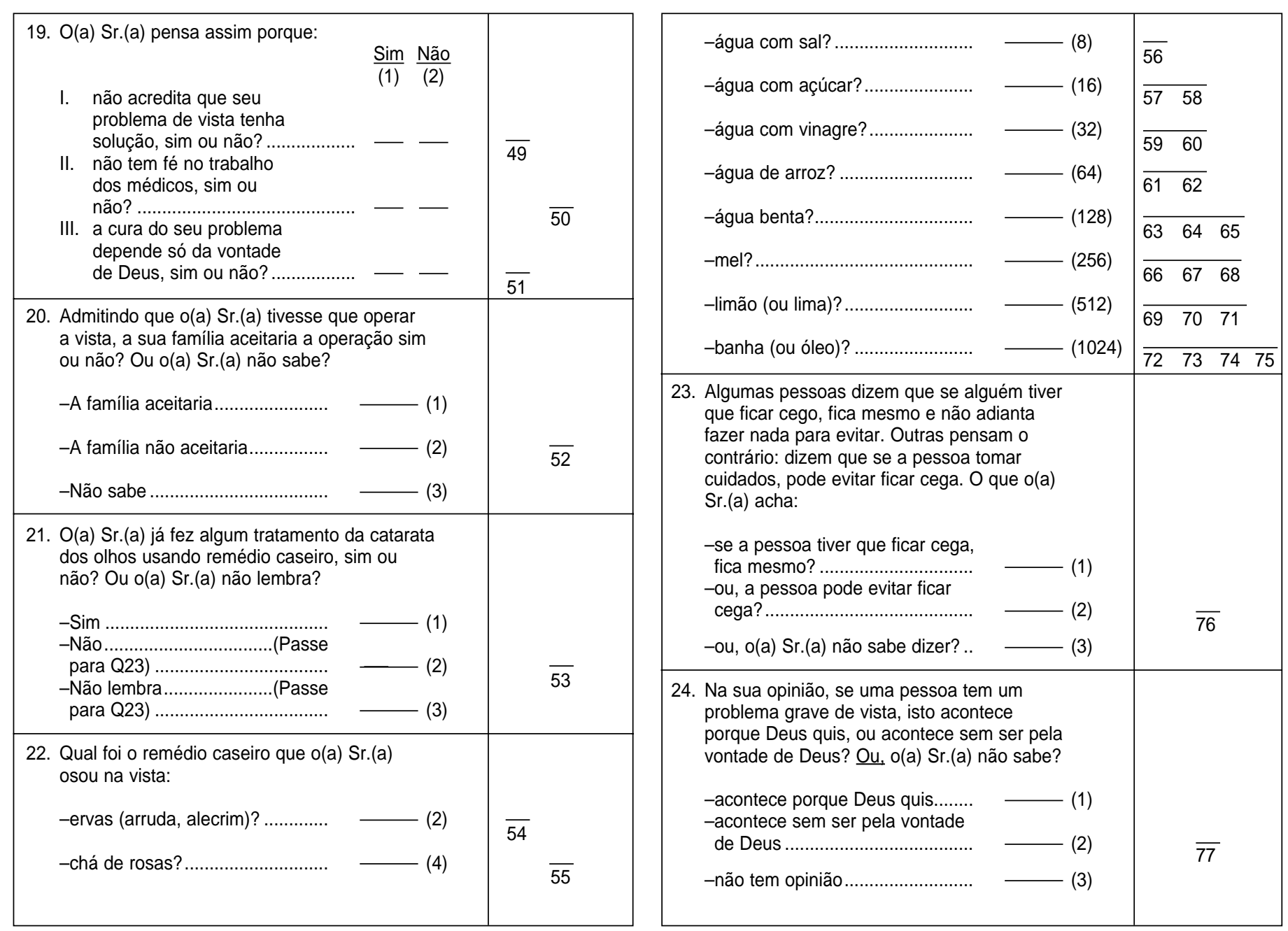

Agradeço a sua atenção.

Data:

ABSTRACT Cataracts are the main cause of blindness in the world, although they can be treated with relatively simple and inexpensive surgery. This study was carried out in 1997 and 1998 in five cities in the state of São Paulo, Brazil, to identify the reasons for per-

\section{Reasons for not having cataract surgery} sons not having cataract surgery. The population studied were patients seen at a community project for the rehabilitation of cataract-caused blindness, Projeto Zona Livre de Catarata (the Cataract-free-Zone Project). A questionnaire was used to interview 776 individuals with cataracts who sought assistance at the project and who had a visual acuity of $20 / 100$ or less in the better eye. Six hundred and eighty-three patients had previously sought ophthalmic care, most frequently $(27 \%)$ at public health services. The main reasons for subjects not having had cataract surgery were financial (69\% of respondents) and the feeling of "still having good eyesight" (69\% of respondents). Among patients who said they were afraid of surgery, the main reason was concern about being left blind. All the subjects whom the project deemed suitable for surgery agreed to undergo the procedure. Apparently, there is a gap between searching for ophthalmic services and the surgical resolution of cataracts. The predominant reasons for not having surgery were financial and logistical. There is a need to facilitate access to cataract surgery by decentralizing social services and by developing community projects to prevent cataract-caused blindness. 